\title{
EVS27
}

Barcelona, Spain, November 17 - 20, 2013

\section{Inductive Battery Charging System for Electric Vehicles}

\author{
Juan Luis Villa ${ }^{1}$, Jose Sanz ${ }^{2}$, Jesús Sallan ${ }^{3}$ \\ ${ }^{1}$ CIRCE Foundation-University of Zaragoza, jvilla@unizar.es \\ ${ }^{2}$ CIRCE Foundation-University of Zaragoza,jfsanz@unizar.es \\ ${ }^{3}$ CIRCE Foundation-University of Zaragoza, jsallan@unizar.es
}

\begin{abstract}
For pure electric vehicles can reach the expected development and have become an alternative to conventional or hybrid vehicles, it is still necessary to solve various problems. The most important are to increase the autonomy of the vehicle and make charging process as quick and clean as possible. Inductive power transfer systems (IPT) can be the solution to these problems, on the one hand, the weight and size limitations of the batteries required for adequate autonomy can be solved with sufficient load points on public roads that allow "recharge" more frequently batteries or even the possibility that these are loaded by dedicated lanes moving. This is only feasible if the loading process requires no human intervention the maneuver faster and safe for the driver.

Furthermore, the ability to recharge the batteries of a contactless EV is now a reality, as evidenced by the high number of patents and published papers, however, for these systems to be part of our daily lives, we need to meet strict international standards for human exposure to electromagnetic fields and, for this, the vehicle must be properly shielded. This paper shows the experimental development of a $30 \mathrm{~kW}$ inductive charger with shielding system and the results obtained.
\end{abstract}

\section{Introduction}

Inductive charging systems for electric vehicles, is an interesting alternative to the plugging systems for different reasons. No need for user intervention in the loading process, is not affected by dust, dirt and moisture and is better protected against vandalism, thus making it cleaner and safer. In the case of purely electric public transport, has a special interest, since the possibility to recharge during stops allow greater autonomy of the vehicle without increasing the weight of batteries needed. The main problem for commercialization currently comes from the hand of the safety of people who may be exposed to high electromagnetic fields. According to international standards ICNIRP maximum magnetic field to which to expose a person depends on the operating frequency. For typical operating frequencies used in charging systems IPT (20-150 kHz) is below the limit of $7 \mu \mathrm{T}$. Depending on the power, this value can be overcome 
in several thousand times, and therefore its use is not possible without a suitable shielding system. This paper shows the analysis of a $30 \mathrm{~kW}$ inductive charging system fully shielded and meets the regulations on exposure to electromagnetic fields and their experimental corroboration mounted on a prototype vehicle.

\section{$2 \quad$ Not shielded IPT}

IPT system comprises two coils, a station located beneath the asphalt and a receiver at the bottom of the vehicle, separated by a distance comparable to the size of coils and magnetically coupled through the air. The behavior is similar to the transformer, but unlike these no iron core is used, the coupling coefficient is very low making it necessary to work at high frequencies and resonance modes, i.e. "tuning" the receiver coil via capacitors to the working frequency.

The equation expressing the amount of power that the secondary of an IPT system can capture is given by [1] which shows the frequency dependence $(\omega 0)$, the current through the transmitter coil (Ip), the factor secondary quality (Qs) and the term representing M2/L2 capture capacity system power:

$$
P_{2}=\frac{\omega_{o} M^{2} Q_{s}}{L_{2}} I_{p}{ }^{2}
$$

The optimal design of the IPT system and resonance topology to use has been widely studied [2,3]. Of all the different topologies, we chose in this work the SP-S topology [4], since it has the best performance when there is a possibility of misalignment between coils, and also presents current source nature, it which is suitable for charging batteries. The scheme of the system (Fig. 1):
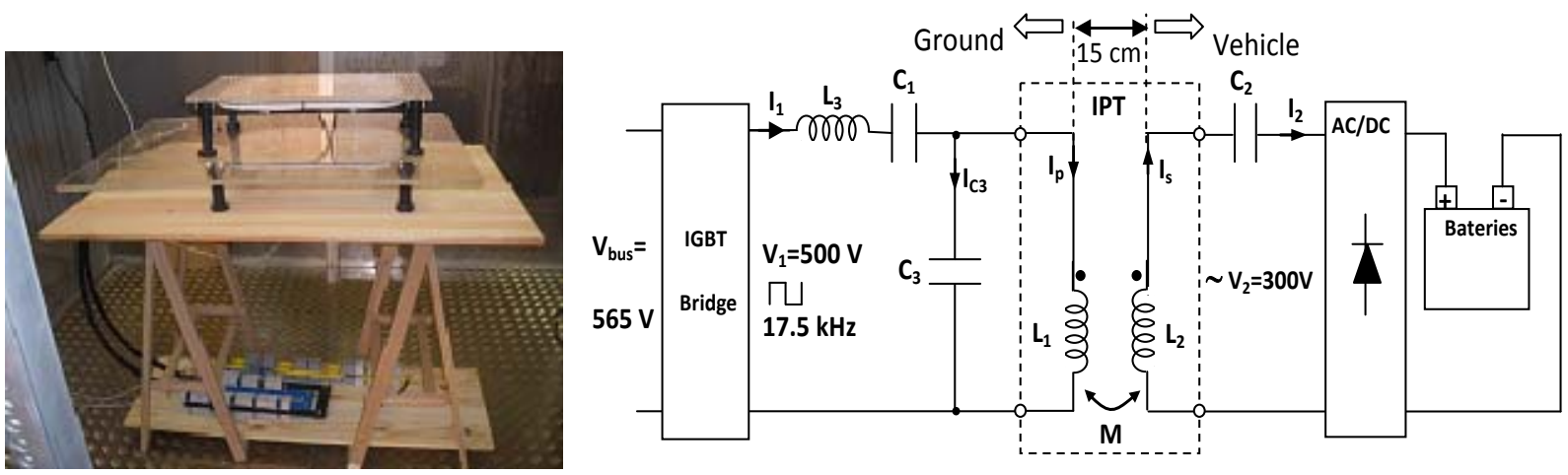

Figure 1: $30 \mathrm{~kW}$ IPT system SP-S compensated. a) prototype, b) schematic

The optimal parameters for the $30 \mathrm{~kW}, 300 \mathrm{~V}$ IPT system, with a transfer distance of $0.15 \mathrm{~m}$ and a coil size of $0.3 \times 0.4 \mathrm{~m}$ is given by [2]:

Table 1: 30 kW IPT Optimal Design Parameters

\begin{tabular}{ccccccccccccc}
\hline & $\begin{array}{c}\mathrm{N} 1 \\
\text { Litz } \\
\text { turns })\end{array}$ & $\begin{array}{c}\mathrm{N} 2 \\
\text { turns }\end{array}$ & $\begin{array}{c}\mathrm{S}_{1} \\
\left(\mathrm{~mm}^{2}\right)\end{array}$ & $\begin{array}{c}\mathrm{S}_{2} \\
\left(\mathrm{~mm}^{2}\right)\end{array}$ & $\begin{array}{c}\mathrm{C}_{1} \\
(\mu \mathrm{F})\end{array}$ & $\begin{array}{c}\mathrm{C}_{2} \\
(\mu \mathrm{F})\end{array}$ & $\begin{array}{c}\mathrm{C}_{3} \\
(\mu \mathrm{F})\end{array}$ & $\begin{array}{c}\mathrm{L}_{1} \\
(\mu \mathrm{H})\end{array}$ & $\begin{array}{c}\mathrm{L}_{2} \\
(\mu \mathrm{H})\end{array}$ & $\begin{array}{c}\mathrm{M} \\
(\mu \mathrm{H})\end{array}$ & $\begin{array}{c}\mathrm{L}_{3} \\
(\mu \mathrm{H})\end{array}$ & $\begin{array}{c}\text { Freq. } \\
(\mathrm{kHz})\end{array}$ \\
\hline Value & 5 & 13 & 100 & 25 & 0.28 & 0.66 & 3.67 & 19.3 & 124 & 8,6 & 220 & 17.5 \\
\hline
\end{tabular}

Figure 2: a) IPT with primary capacitors $\mathrm{C}_{1}, \mathrm{C}_{3}$

Testing the system safety was necessary to mount inside an aluminum cage. When the system is transferring the power rating, the magnetic field emitted exceeds the maximum allowed even at distances of $2 \mathrm{~m}$ invading the interior of the vehicle as shown in figure 2. 

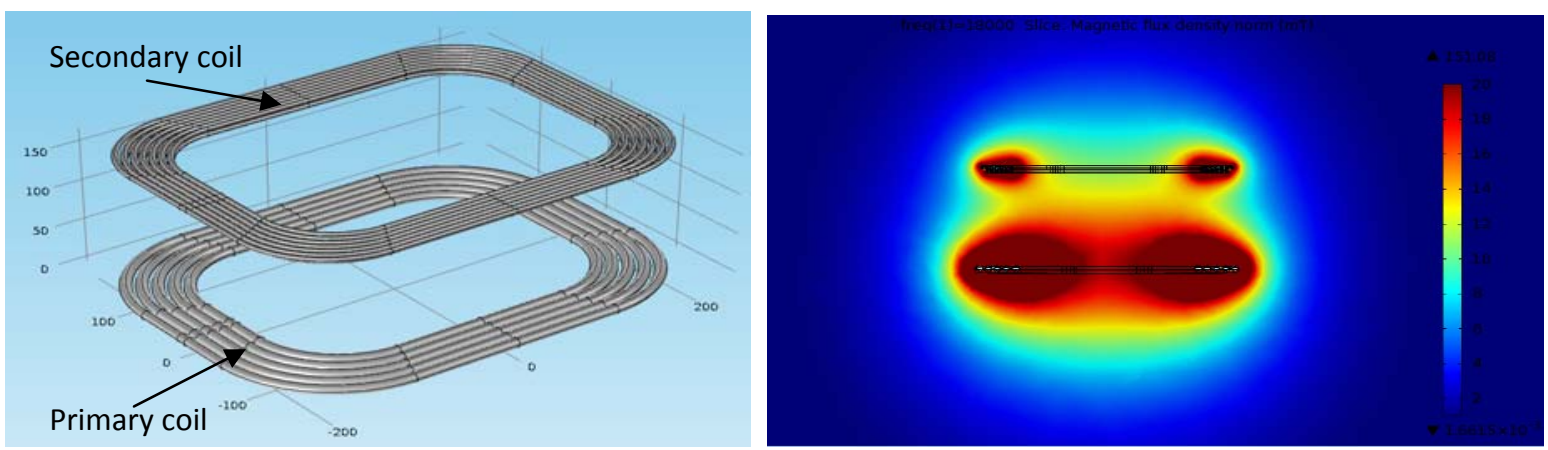

Figure 2: a) coils without shielding b) magnetic field distribution up $150 \mathrm{mT}$

\section{$3 \quad$ Shielded IPT}

To prevent the driver or passengers are subjected to magnetic field levels higher than allowed, you need a suitable shielding system. Proper design must meet two basic conditions: first, not to miss the magnetic field and secondly, that the power transfer conditions are not affected.

For the first condition is sufficient to surround the emitting and receiving coils with a conductive diamagnetic material which induces Eddy current that generates a magnetic field opposite to the main [5]. At low power, it can use a simple aluminum plate between the receiver coil and the vehicle floor so that the field does not leak into the passenger compartment (Fig. 3) does not require a high thickness as the working frequency, skin effect causes said current focus on the face closest to the coils.
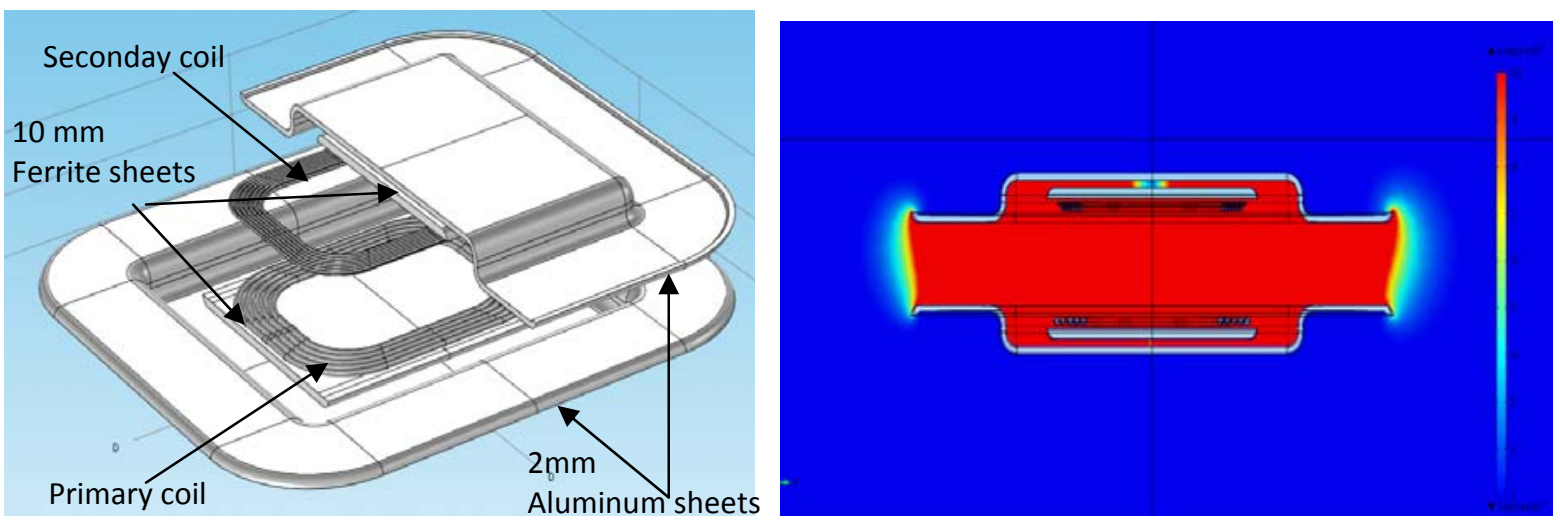

Figure 3: a) coils with Al-Ferrite shielding b) distribucción de campo magnético superior a $10 \mu \mathrm{T}$ (red)

However, the presence of aluminum modifies the coil magnetic circuit considerably reducing the inductance values of $M$ and $\mathrm{L}_{2}$. This decrease is not proportional, making $\mathrm{M}^{2} / \mathrm{L}_{2}$ term is less than without aluminum and according to ec.1, the power that the system is capable of transferring to the load decreases considerably. So if we want the power transferred to the load remains the nominal value, it's necessary to include a ferromagnetic material that increase the values of $M$ and $L_{2}$, for example ferrite, whose permeability is several thousand times higher than the vacuum and its conductivity is very low making negligible losses associated with induced currents (Fig. 3). The inclusion of ferrite in the magnetic circuit has the task not to shield because this is achieved with aluminum, but to counteract the decrease of the values of $\mathrm{M}$ and $\mathrm{L}_{2}$ produced by the aluminum.

Table 2: $\mathrm{M}^{2} / \mathrm{L}_{2}$ with and without shielding

\begin{tabular}{cccc}
\hline & $\mathrm{L}_{2}(\mu \mathrm{H})$ & $\mathrm{M}(\mu \mathrm{H})$ & $\mathrm{M}^{2} / \mathrm{L}_{2}$ \\
\hline without shielding & 124 & 8.6 & 0.596 \\
\hline aluminum shielding & 61 & 1.2 & 0.024 \\
\hline Aluminum and ferrite shielding & 195 & 10.8 & 0.598 \\
\hline
\end{tabular}


In Table 2, is shown as with a suitable combination Al-ferrite plates, the power transfer capacity is the same as without shielding. To design the position, size, distance, thickness ......, ferrites of aluminum, it is necessary the use of 3D finite element programs.

The design and position of the different materials not only must be taken into account to shield and retain the ability to transfer power, but no magnetic saturation occurs at any point of the ferrites (which results in the loss of linearity) and the maximum current density in the aluminum can not lead to melting point.
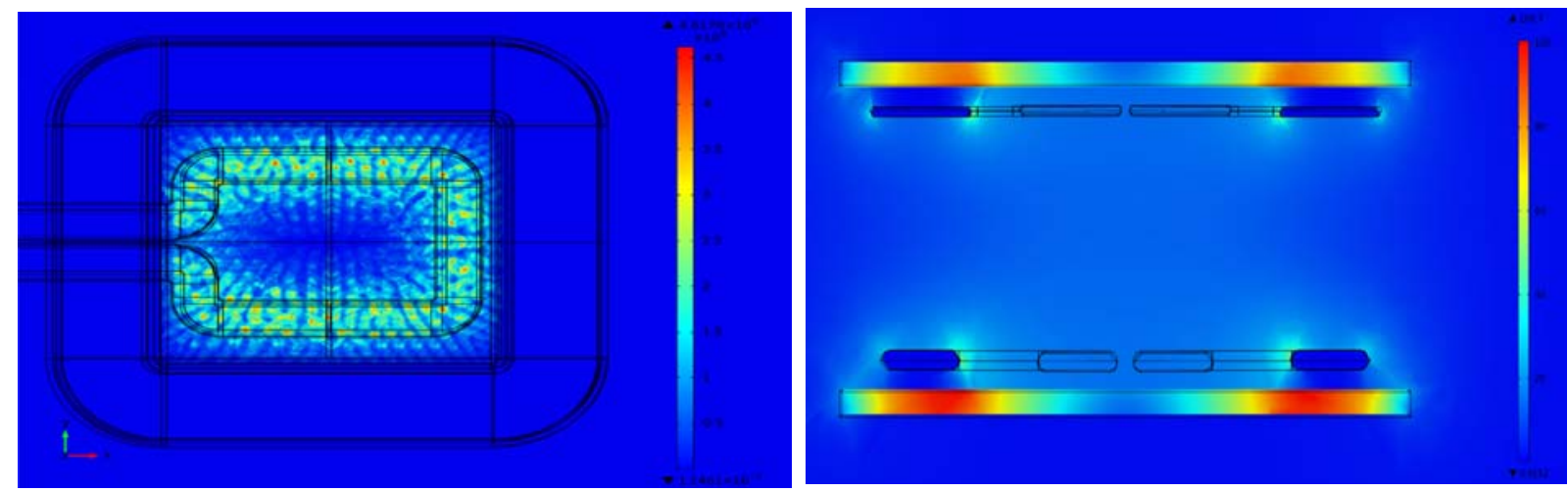

Figure 5: a) Máxima densidad de corriente en el aluminio b) máximo campo magnético en las ferritas

Fig. 5 shows that for the $30 \mathrm{~kW}$ prototype maximum current density is $4.5 \mathrm{~A} / \mathrm{mm} 2$ (red dots) and the maximum magnetic field inside the ferrite is $0.1 \mathrm{~T}$ (red lower ferrite) values both below limits for hazardous materials work.

\section{References}

[1] J. Villa, J. Sallán, A. Llombart and J. Sanz, Design of a high frequency Inductively Coupled Power Transfer system for electric vehicle battery charge, Applied Energy, ISSN: 0306-2619, 86 (2009), 355-363.

[2] J.Sallán, J.Villa, A. Llombart, and J. Sanz, Optimal Design of ICPT Systems Applied to Electric Vehicle Battery Charge, IEEE Transactions on Industrial Electronics, ISSN 0278-0046, 56(2009), 2140-2149.

[3] H. Matsumoto, Y. Neba, K. Ishizaka and R. Itoh, Comparison of Characteristics on Planar Contactless Power Transfer System, IEEE Transactions on Industrial Electronics, ISSN 0885-8993 ,27(2012) , 2980-2993.

[4] J. Villa, J. Sallán, J. Sanz and A. Llombart, High-Misalignment Tolerant Compensation Topology For ICPT Systems, IEEE Transactions on Industrial Electronics, ISSN 0278-0046 , 59(2012), 945- 951.

[5] M. Budhia, G.A. Covic and J. Boys, Design and Optimizacion of Circular Magnetic Structures for Lumped Inductive Power Transfer , IEEE Transactions on Industrial Electronics, ISSN 0885-8993, 26 (2011), 3096- 3108

\section{Authors}

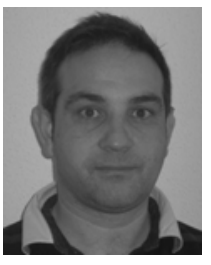

Juan L. Villa was born in Zaragoza, Spain, in 1966. He received the M.E. degree in industrial engineering, and the Ph.D. in industrial engineering from the University of Zaragoza, Spain, in 1997 and 2009 respectively. He is currently a Researcher in Energy Engineering with CIRCE and Lecturer at the Electrical Engineering Department, University of Zaragoza. His research interests include inductive power transfer, electric drives, electric vehicles and renewable energy integration.

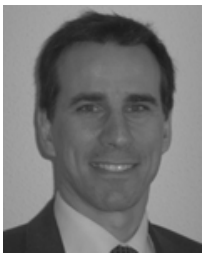

José F. Sanz was born in Tarrasa, Spain, in 1967. He received the M.E. degree in industrial engineering, and the Ph.D. in electrical enginnering from the University of Zaragoza in 1992, 1995 and 2007, respectively. He is currently the Deputy Director with the Electrical Division of CIRCE and a Lecturer at the Electrical Engineering Department, University of Zaragoza. His research interests are renewable energy integration, high efficiency energy storage systems and grid connection systems (FACTS and FAPS).

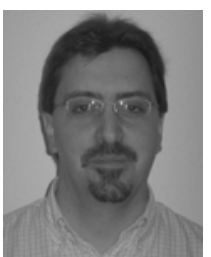

Jesús Sallán was born in Zaragoza, Spain, in 1971. He received the M.E. degree in industrial engineering and the Ph.D. in electrical engineering from the University of Zaragoza, Spain, in 1995 and 2002, respectively. He is currently a Researcher in Energy Engineering with CIRCE and a Lecturer at the Electrical Engineering Department, University of Zaragoza. His research interests include inductive power transfer, electric machine control, variable speed generation and renewable energy. 